\title{
Phytoprotection
}

\section{Index des auteurs, volume 82 Author Index, Volume 82}

Volume 82, numéro 3, 2001

URI : https://id.erudit.org/iderudit/706224ar

DOI : https://doi.org/10.7202/706224ar

Aller au sommaire du numéro

Éditeur(s)

Société de protection des plantes du Québec (SPPQ)1

ISSN

0031-9511 (imprimé)

1710-1603 (numérique)

Découvrir la revue

Citer ce document

(2001). Index des auteurs, volume 82. Phytoprotection, 82(3), 141-142.

https://doi.org/10.7202/706224ar d'utilisation que vous pouvez consulter en ligne.

https://apropos.erudit.org/fr/usagers/politique-dutilisation/ 


\section{Index des auteurs, volume 82 Author Index, Volume 82}

\section{A-B}

Abney, T.S.

Arul, J.

Bacon, R.

Baird, R. E.

Bauce, É.

Beaulieu, C.

Bélair, G.

Bélanger, R.R.

Benhamou, N.

Bernier, J.

Bernier, L.

Berthiaume, R.

Bin, J.

Bishop, S.D.

Bok, S.H.

Borden, J.H.

Bostanian, N.J.

Breuil, C.

Brodeur, J.

Brzezinski, R.

\section{C-D}

Carisse, $\mathrm{O}$.

Cavanagh, M.-H.

Chabot, R.

Chabot, V.

Charest, $\mathrm{M}$.

Chen, X.

Chinn, J.M.

Clarke, B.B.

Comeau, A.

Côté, J.-C.

Crawford, D.L.

Coulombe, C.

Couture, L.

Dauphinais, $\mathrm{N}$.

Dewey, F.M.

Dionne, I.

Dionne, J.

Djuric-Ciganovic, S.

Dostaler, D.

Doumbou, C.L.

$123,124,134$

131

41

125

130

135

113

125

131

73

85

$57,128,130$

130

49

129

127

133

135

130

85

113

57

Duke, G.M.

Dupont, A.

\section{E-K}

1 Errampalli, D. 103

41 Fayad, K.P. 133

Feau, N. $\quad 127$

Filion, $\mathrm{P}$. $\quad 35$

Fortin, M.G. $\quad 129$

Fournier, Y. $\quad 49$

Gibson, G. $\quad 65$

Goettel, M.S. $\quad 113$

Goulet, H. $\quad 65$

Hamby Salove, M.K. $\quad 85$

Hamelin, R.C. $\quad 132$

Hébert, C. $\quad 57$

Hervieux, V. 41

Huber, J. $\quad 65$

Jobin, L. $\quad 57$

Jordan, M. $\quad 135$

Kushalappa, C. 129

\section{L-P}

Lavallée, $\mathrm{R}$.

128,130

Lemieux, C. $\quad 125$

Leroux, G.D. $\quad 125$

LeSage, L. $\quad 35$

Loppnau, P. $\quad 129$

Martinez, C. $\quad 128$

Mauléon, $\mathrm{H}$. $\quad 49$

McKeown, A.W. 13

Meloche, F. $\quad 35$

Michaud, M. 128

Mohr, A. $\quad 129$

Morin, C. 129

Mottet, M.J. 127

Mullinix, B.G. 1

Nguyen, T.T.A. 130

Nicole, M.-C. 130

Noronha, C. 113

Pan, R.I. $\quad 135$

Périnet, $P$. $\quad 127$

Plourde, K. 131

Potter, J.W. 13

Pouleur, S. $\quad 131$ 


\section{R-Y}

Racette, G. 25

Rioux, D. 132

Saint-Michel, E. $\quad 132$

Saunders, J.M. 103

Sharkey, M. $\quad 65$

Shetlar, D.J. $\quad 133$

Simao-Beaunoir, A.-M. 133

Simard, L. $\quad 133$

Simard, M. 132

Smith R.F. $\quad 65$

Son, K.-H. 73

Talbot, B.G. 123, 124, 134

Tremblay, G. $\quad 35$

Tremblay, M. 134

Tweddell, R.J. $\quad 41,128$

Vincent, C. $\quad 65,73$

Wang, $X$. 135

Watson, A.K. 134

Wen, B. 135

Xing, T. $\quad 135$ 